\title{
Preparation of Calcium Phosphate-Biodegradable Polymer Composites with Ion-Releasing Ability for Enhancing Bone Formation*1
}

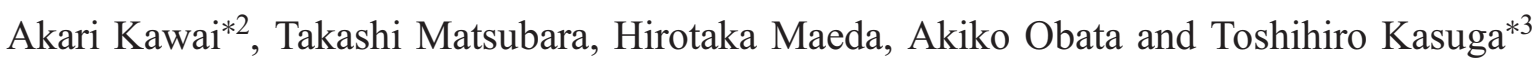 \\ Division of Advanced Ceramics, Nagoya Institute of Technology, Nagoya 466-8555, Japan
}

\begin{abstract}
An inorganic-organic composite material, consisting of bioresorbable $\beta$-tricalcium phosphate $(\beta$-TCP) and a biodegradable polymer, is one of the most important materials for use in artificial bone with good shapability. In this work, to activate bone-forming cells immediately after being implanted in a living body, the ability to release therapeutic ions, such as $\mathrm{Ca}^{2+}, \mathrm{Mg}^{2+}$, and silicate ions was incorporated in the composite material. A small amount (8vol\%) of $46.1 \mathrm{SiO}_{2} \cdot 24.4 \mathrm{Na}_{2} \mathrm{O} / \mathrm{MgO} \cdot 26.9 \mathrm{CaO} \cdot 2.6 \mathrm{P}_{2} \mathrm{O}_{5}$ (mol\%) glass particles was embedded successfully into the composite material. When the glass particles containing $\mathrm{Na}_{2} \mathrm{O}$ were included in the material, the molecular weight of the polymer in the matrix phase was severely reduced and its hydrolysis in Tris- $\mathrm{HCl}$ buffer solution was drastically accelerated. On the other hand, when the glass particles containing $\mathrm{MgO}$ were included, therapeutic ions were continuously released with almost no change in the buffer solution $\mathrm{pH}$. The released amount of silicate ions was well controlled, to avoid excessive dissolution, compared to those of $\mathrm{Ca}^{2+}$ and $\mathrm{Mg}^{2+}$ ions. Therefore, the glass particle is one of the most promising candidates to be a source in the composite for releasing therapeutic ions that enhance bone formation. [doi:10.2320/matertrans.Y-M2020859]
\end{abstract}

(Received June 23, 2020; Accepted October 8, 2020; Published November 30, 2020)

Keywords: composite, tricalcium phosphate, glass, biodegradable polymer, ion release

\section{Introduction}

$\beta$-tricalcium phosphate $(\beta$-TCP), that has excellent osteoconductivity and bioresorbability, is widely used as an implant material in bone defects. ${ }^{1)}$ Recently, various inorganic-organic composite materials have also been developed. ${ }^{2,3)}$ Composite materials, in whose structure the $\beta$-TCP particles are embedded in the polymer as a matrix phase, often have unimproved mechanical brittleness. ${ }^{4)}$ However, since the composite materials can be easily processed into desired shapes, various applications are expected. Typical biodegradable polymers include poly(lactic acid $)^{5)}$ and poly(lactic-co-glycolic acid). ${ }^{6-8)}$ Copolymers containing L- and D-lactides (PDLLGA) are amorphous and highly biodegradable, and may also have water swelling properties. ${ }^{9)}$

In recent years, enhancement of the bone-forming ability, for improving therapeutic effects, has become important. One of the concepts is that, when a biomaterial is implanted in a living body, some substances are released to genetically activate the bone-forming cells. These substances also accelerate the bone-forming process through their adhesion, proliferation, differentiation, and mineralization. Examples of these substances, include some proteins and amino acids, or inorganic ions (so-called therapeutic ions; $\mathrm{Ca}^{2+}, \mathrm{Mg}^{2+}$, silicate ions, etc.). ${ }^{10)}$ Inorganic ions are useful since they do no denature during material synthesis nor change over time during storage. Therefore, $\beta$-TCP/biodegradable polymer composite material is expected to be one of the most important materials as an artificial bone for a super-aging society. This is because it can be used for activating boneforming cells by releasing therapeutic ions immediately after implantation in a living body.

\footnotetext{
${ }^{* 1}$ This Paper was Originally Published in Japanese in J. Jpn. Soc. Powder Powder Metallurgy 67 (2020) 278-283.

${ }^{* 2}$ Graduate Student, Nagoya Institute of Technology

${ }^{* 3}$ Corresponding author, E-mail: kasuga.toshihiro@nitech.ac.jp
}

Bioglass ${ }^{\circledR} \quad 45 \mathrm{~S} 5$ developed by Hench et al., with a composition of $46.1 \mathrm{SiO}_{2} \cdot 24.4 \mathrm{Na}_{2} \mathrm{O} \cdot 26.9 \mathrm{CaO} \cdot 2.6 \mathrm{P}_{2} \mathrm{O}_{5}$ in mol\%, has excellent bioactivity, that is, the ability to chemically bond with bones. When $45 \mathrm{~S} 5$ is implanted in a living body, it releases inorganic ions, such as $\mathrm{Na}^{+}, \mathrm{Ca}^{2+}$, silicate and phosphate ions as it gradually dissolves. ${ }^{11)}$ By implanting a silicate glass with a low silica content, such as 45S5 into a living body, ${ }^{12)} \mathrm{Na}^{+}$and $\mathrm{Ca}^{2+}$ ions are released immediately by ion exchange with protons in the body fluid. Subsequently, many silanol (Si-OH) groups are formed along with this reaction and results in a silica gel layer forming on the glass surface through the condensation of the $\mathrm{Si}-\mathrm{OH}$ groups. Therefore, the release of silicate ions is gradually controlled.

We prepared a PDLLGA composite material containing $40 \mathrm{SiO}_{2} \cdot 40 \mathrm{MgO} \cdot 20 \mathrm{Na}_{2} \mathrm{O}$ glass particles as the source of silicate and $\mathrm{Mg}^{2+}$ ions while calcium carbonate (vaterite) particles were used as the $\mathrm{Ca}^{2+}$ ions source. ${ }^{13)}$ When the material was soaked in a cell culture medium, the surface of the vaterite particles was covered with a silica gel layer, that had originated from the silicate ions released from the glass particles. This gel layer controlled the release of excess $\mathrm{Ca}^{2+}$ ions from vaterite immediately after being soaked. As a result, a material with an ability to supply $\mathrm{Ca}^{2+}$ ions for a long period of time could be obtained.

Therefore, we aim to develop a material that can activate bone-forming cells earlier after implantation in a living body and then shift smoothly to bone remodeling. We intend to prepare a material in which a small amount of the glass particles is embedded with $\beta$-TCP particles in the PDLLGA matrix phase.

In this work, two kinds of composite materials were prepared using $45 \mathrm{~S} 5$ and a glass in which $\mathrm{Na}_{2} \mathrm{O}$ in the $45 \mathrm{~S} 5$ composition was completely substituted with $\mathrm{MgO}$. The ion releasing behavior, when soaked in a Tris- $\mathrm{HCl}$ buffer solution, was investigated, and the behavior of a glass suitable for preparing a composite material was discussed. 


\section{Experimental Procedure}

\subsection{Preparation of glass particles}

45S5 glass $\left(46.1 \mathrm{SiO}_{2} \cdot 24.4 \mathrm{Na}_{2} \mathrm{O} \cdot 26.9 \mathrm{CaO} \cdot 2.6 \mathrm{P}_{2} \mathrm{O}_{5}\right.$ in mol\%: denoted by $\mathrm{BG}-\mathrm{Na})$ and a glass $\left(46.1 \mathrm{SiO}_{2} \cdot 24.4\right.$ $\mathrm{MgO} \cdot 26.9 \mathrm{CaO} \cdot 2.6 \mathrm{P}_{2} \mathrm{O}_{5}$ in mol\%: denoted by $\mathrm{BG}-\mathrm{Mg}$ ), in which $\mathrm{Na}_{2} \mathrm{O}$ was substituted with $\mathrm{MgO}$, were prepared. The chemical reagents weighed as a glass yield of $20 \mathrm{~g}\left(\mathrm{SiO}_{2}\right.$ : 99.0\%, $\mathrm{Na}_{2} \mathrm{CO}_{3}$ : 99.8\%, $\mathrm{MgO}: 98.0 \%, \mathrm{CaCO}_{3}: 99.5 \%$, $\mathrm{H}_{3} \mathrm{PO}_{4}: 85.0 \%$ (liquid), Kishida Chemical) were placed in a Teflon ${ }^{\circledR}$ beaker. Then, distilled water was added to make a slurry, that was then stirred to mix. The slurry was then dried overnight under an infrared lamp. The resulting dried mixture was placed in a platinum crucible and melted in an electric furnace at $1500^{\circ} \mathrm{C}$ for $30 \mathrm{~min}$ in air. After melting, the mixture was cast on a stainless-steel plate and the resulting glass was quenched by the iron pressing method. All the resulting glass pieces, $400 \mathrm{~g}$ of zirconia balls with a diameter of $3 \mathrm{~mm}$, and $150 \mathrm{~mL}$ of methanol (Kishida Chemical) were placed into a zirconia pot, with a volume of $300 \mathrm{~mL}$, and crushed by a uniaxial ball-milling for $24 \mathrm{~h}$. The resulting powder was then dried at $80^{\circ} \mathrm{C}$.

To examine whether the resulting powder was amorphous, powder X-ray diffractometry (XRD: X'pert-MPD, Malvern Panalytical) was performed. The glass compositions were analyzed by energy dispersive X-ray analysis (EDX: JED2300, JEOL) $(n=5)$. Each glass transition temperature, $T_{g}$ was determined by differential thermal analysis (DTA: Thermoplus TG8120, Rigaku). Laser Raman spectroscopy (LRS: NRS-3300 using Nd: YAG laser, JASCO) was also performed to determine the structure of the glasses.

\subsection{Preparation of composite materials}

PDLLGA with a (lactic acid):(glycolic acid) ratio of 75:25 was used (Purasorb ${ }^{\circledR}$ PDLG7509, Corbin). This was dissolved in hexafluoro-2-propanol, and then $\beta$-TCP $(\beta$ TCP100 crushed product, Taihei Chemical Industry) and the glass powder (BG-Na or BG-Mg) were mixed to make a slurry. The composition in volume ratio of BG-Na or BGMg: $\beta$-TCP:PDLLGA was $8: 42: 50$. The slurry was then put in a zirconia ball mill pot with a volume of $45 \mathrm{~mL}$, and then mixed for $5 \mathrm{~min}$ with a rotation/revolution-type milling (socalled planetary ball-milling) device without balls. After mixing, the slurry was cast in a Teflon ${ }^{\circledR}$ container, with a diameter of $80 \mathrm{~mm}$, and then dried at $80^{\circ} \mathrm{C}$ for $24 \mathrm{~h}$, resulting in the formation of a film.

Gel permeation chromatography (GPC: HLC-8320GPC, Tosoh) was performed to measure the molecular weight of the polymer in the prepared composite materials. Initially, the material was mixed with chloroform (Reagent Grade, Wako Pure Chemical) to make a slurry, that was then filtered with a Teflon ${ }^{\circledR}$ filter $(\mathrm{H}-13-5$, pore size: $0.5 \mu \mathrm{m}$, Tosoh). A sample concentration of $2 \mathrm{mg} / \mathrm{mL}$, flow rate of $0.6 \mathrm{~mL} / \mathrm{min}$, and column temperature of $40^{\circ} \mathrm{C}$ were used. Polystyrene (PStQuick ${ }^{\circledR}$ C, D, Tosoh) was used as the standard sample.

The film-shaped composite material $(10 \times 10 \mathrm{~mm}$, thickness: $0.63 \pm 0.1 \mathrm{~mm}$, weight: $110 \pm 14 \mathrm{mg}$ ) was soaked in $10 \mathrm{ml}$ of Tris- $\mathrm{HCl}$ buffer solution (TBS). This was then stirred at $37^{\circ} \mathrm{C}$ using a shaking incubator (KS4000i, IKA) for a predetermined period $(n=3)$. The mixture was filtered, and the sample that was retained by the filter paper was then dried at room temperature $\left(22 \sim 27^{\circ} \mathrm{C}\right)$. The solution $\mathrm{pH}$, after the soaking, was measured. Meanwhile, the concentrations of $\mathrm{Ca}^{2+}, \mathrm{Mg}^{2+}$, silicate, and phosphate ions were measured by inductively coupled plasma optical emission spectrometry (ICP-OES: ICPS-7000, Shimadzu). Silicon and phosphorus existed as silicate and phosphate ions in the solution. In this work, they were measured and presented as $\mathrm{Si}^{4+}$ and $\mathrm{P}^{5+}$ for convenience.

The samples before and after 7 days of soaking were sliced by a focused ion beam method (FIB: EM-9320FIB, JEOL) to observe their cross-sections using a transmission electron microscope (TEM: JEM-2100F, JEOL). The compositions of some portions in the images were examined using an incorporated energy dispersive X-ray spectrometer (EDX).

\section{Results}

\subsection{Compositions and structures of glasses}

The XRD patterns and LRS spectra of the resulting glasses, and analyzed glass compositions with their glass transition temperatures $\left(T_{g} \mathrm{~s}\right)$ are shown in Figs. 1(a), (b), and Table 1, respectively. Both $\mathrm{BG}-\mathrm{Na}$ and $\mathrm{BG}-\mathrm{Mg}$ showed glass-derived halo peaks; no crystals were included. EDX

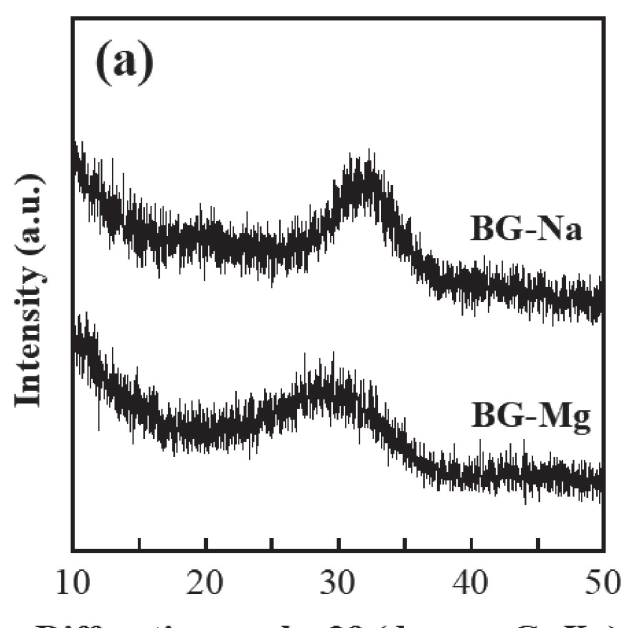

Diffraction angle, $2 \theta($ degree, $\mathrm{CuK} \alpha)$

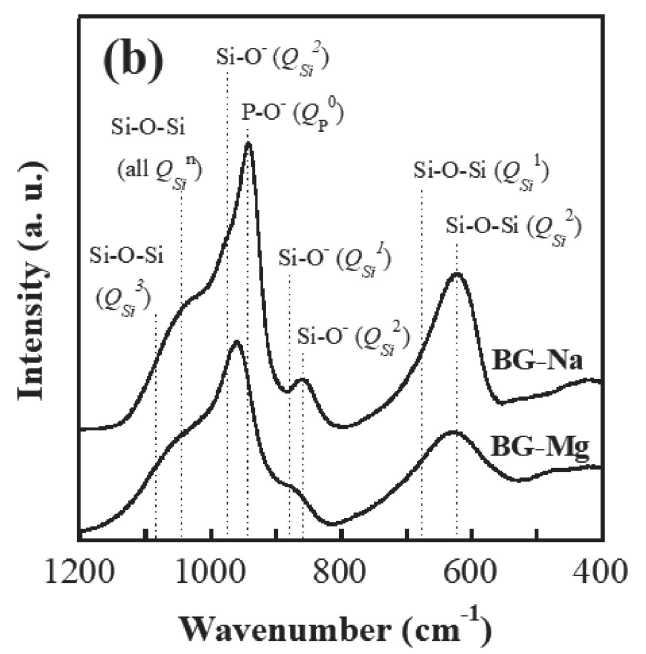

Fig. 1 (a) XRD patterns and (b) LRS spectra of BG-Na and BG-Mg 
Table 1 Nominal and analyzed compositions in mol\% of BG-Na and BG-Mg and their glass transition temperatures $\left(T_{g}\right)$. The analyzed compositions are shown with standard deviation.

\begin{tabular}{ccccccc}
\hline \multirow{2}{*}{ Glass code } & \multicolumn{4}{c}{ Composition (mol\%, upper: nominal, lower: analyzed) } & \multirow{2}{*}{$\mathrm{Tg}(\mathrm{K})$} \\
\cline { 2 - 5 } & $\mathrm{SiO}_{2}$ & $\mathrm{Na}_{2} \mathrm{O}$ & $\mathrm{MgO}$ & $\mathrm{CaO}$ & $\mathrm{P}_{2} \mathrm{O}_{5}$ & \\
\hline \multirow{2}{*}{$\mathrm{BG}-\mathrm{Na}$} & 46.1 & 24.4 & & 26.9 & 2.6 & 804 \\
& $47.8 \pm 0.2$ & $23.3 \pm 0.9$ & - & $25.9 \pm 0.8$ & $3.0 \pm 0.1$ & \\
BG-Mg & 46.1 & & 24.4 & 26.9 & 2.6 & 983 \\
\hline
\end{tabular}

analysis showed that the glasses, with compositions close to the nominal ones, were obtained.

The positions of the halo peaks shown in the XRD patterns (Fig. 1(a)) were slightly different in both cases, implying that their structures were different. $T_{g} \mathrm{~s}$ were also different between the glasses. The numbers, $n$, of the bridging oxygen around $\mathrm{Si}$ and $\mathrm{P}$ were expressed as $Q_{S i}{ }^{n}$ and $Q_{P}{ }^{n}$, respectively, in the LRS spectra (Fig. 1(b)). As shown, the peaks due to $Q_{S i}{ }^{1}, Q_{S i}{ }^{2}, Q_{S i}{ }^{3}$, and $Q_{S i}{ }^{n}$ were observed around 680 and $870 \mathrm{~cm}^{-1} ;{ }^{14,15)}$ 630, 860-870, and $980 \mathrm{~cm}^{-1} ;{ }^{15-17)} 1080$ $\mathrm{cm}^{-1}{ }^{14)}$ and $1040 \mathrm{~cm}^{-1}{ }^{14)}$ respectively. The peaks ${ }^{14)}$ due to $Q_{P}{ }^{0}$ were also observed around $940-960 \mathrm{~cm}^{-1}$. Meanwhile, the spectrum of BG-Mg showed the characteristic shifts of the $\mathrm{Si}-\mathrm{O}^{-}$peak, ${ }^{17)}$ originating from $Q_{S i}{ }^{2}$ around $860 \mathrm{~cm}^{-1}$ and the $\mathrm{P}-\mathrm{O}^{-}$peak $^{14)}$ from $Q_{P}{ }^{0}$ around $940 \mathrm{~cm}^{-1}$. The electric field strength, $F$, proposed by Dietzel is shown in eq. (1). ${ }^{18)}$

$$
F=z / a^{2}
$$

where $z$ is the valence of positive ions, and $a$ is the distance (A) between the positive and negative ions. The $F$ s of 6 fold-coordinated $\mathrm{Na}^{+}, 8$-fold-coordinated $\mathrm{Ca}^{2+}$, and 6-foldcoordinated $\mathrm{Mg}^{2+}$ ions were $0.15,0.31$ and 0.44 , respectively, showing that there were variation in their bond strengths. The peak shifts mentioned above were due to the difference in the cation coordinated to the non-bridging oxygen.

\subsection{Inorganic ion release behaviors from composite materials}

Table 2 shows the molecular weights (weight average molecular weight $M w$ and polydispersity $M w / M n)$ of PDLLGA in the resulting composite materials. Compared to as-received PDLLGA, when BG-Na was included, the $M w$ decreased by two orders of magnitude. Even when BG-Mg was included, the $M w$ was almost half. Their polydispersities also increased.

Table 2 Weight-average molecular weights $(\mathrm{Mw})$ and polydispersities $(\mathrm{Mw} / \mathrm{Mn})$ of as-received PDLLGA and PDLLGA in the resulting composites. Mn means number-average molecular weights.

\begin{tabular}{ccc}
\hline Sample code & Mw (kDa) & Mw/Mn \\
\hline PDLLGA & 126.7 & 1.86 \\
BG-Na/TCP/PDLLGA & 1.4 & 2.10 \\
BG-Mg/TCP/PDLLGA & 71.3 & 1.95 \\
\hline
\end{tabular}

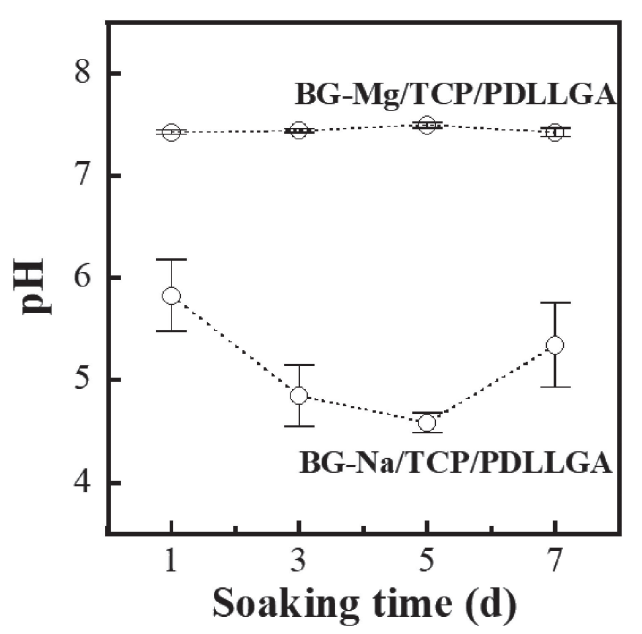

Fig. $2 \mathrm{pH}$ after soaking the composites in Tris- $\mathrm{HCl}$ buffer solution. Initial $\mathrm{pH}$ of the solution is 7.40 .

Figure 2 shows the $\mathrm{pH}$ values of TBS when the filmshaped composite materials were soaked. When BG-Mg/ TCP/PDLLGA was soaked, the $\mathrm{pH}$ values were almost unchanged, whereas in the case of BG-Na/TCP/PDLLGA, the $\mathrm{pH}$ greatly decreased.

Figure 3 shows the inorganic ion amounts in TBS when the film-shaped BG-Mg/TCP/PDLLGA was soaked. $\mathrm{Ca}^{2+}$ and $\mathrm{Mg}^{2+}$ ions were released almost linearly with increase in soaking time. Judging from the BG-Mg glass composition, the released amount of $\mathrm{Si}^{4+}$ ions was controlled at a considerably low level. Almost no $\mathrm{P}^{5+}$ ions were measured; this is due to the low $\mathrm{P}_{2} \mathrm{O}_{5}$ content in the glass and the low glass content in the composite.

Figure 4 is a cross-sectional TEM photograph (bright field image) around the surface of the BG-Mg/TCP/PDLLGA film before and after being soaked in TBS. The EDX spectra implied that the sharp and fine particles, portion (a), before the soaking were BG-Mg glass and the relatively large particles, portion (b), were $\beta$-TCP. The inorganic particles were embedded in the dense polymer phase; there were no large-sized voids. On the other hand, many voids were observed after $7 \mathrm{~d}$ of soaking. Almost no sharp particles were observed, while fine particles of $\sim 0.5 \mu \mathrm{m}$ or less in size, as shown in the portion (c), were observed. The EDX spectrum of portion (c) showed that $\mathrm{Si}$ was the major component with almost no $\mathrm{Ca}$ and $\mathrm{Mg}$ present. 


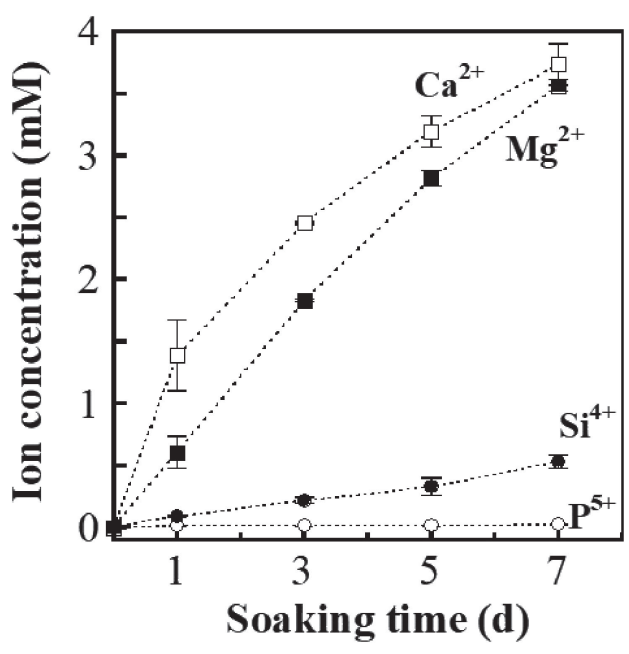

Fig. 3 Ion amounts in Tris- $\mathrm{HCl}$ buffer solution after soaking BG-Mg/ TCP/PDLLGA.

\section{Discussion}

It has been reported that, in silicate glasses with low $\mathrm{P}_{2} \mathrm{O}_{5}$ contents, $\mathrm{Na}^{+}$ions are preferentially coordinated to nonbridging oxygens in the phosphate groups. ${ }^{19)}$ Meanwhile, when $\mathrm{Ca}^{2+}$ and $\mathrm{Mg}^{2+}$ ions coexist, it has been reported that $\mathrm{Ca}^{2+}$ ions are preferentially coordinated to the non-bridging oxygens in the phosphate groups. ${ }^{20,21)}$ These reports insinuate that $\mathrm{Ca}^{2+}$ ions in $\mathrm{BG}-\mathrm{Mg}$ are coordinated to the phosphate groups, instead of $\mathrm{Na}^{+}$ions in BG-Na, and that the amount of silicate groups coordinated with $\mathrm{Mg}^{2+}$ ions increased. Depending on the glass composition, some of the intermediate $\mathrm{MgO}$ acts as a glass network former. ${ }^{22)}$ It is possible that some $\mathrm{Mg}^{2+}$ ions entered the glass network, resulting in the formation of $\mathrm{Si}-\mathrm{O}-\mathrm{Mg}$ bonds. Due to such difference in glass structure, the durability of BG-Mg against aqueous solutions was supposed to be higher than that of BG-Na.

Practically, BG-Na particles show are highly hygroscopic, therefore careful handling is required to avoid their hydration. During the mixing process in the preparation of the composite materials, the basicity around the surface of the glass particles increased due to the dissolution of $\mathrm{Na}^{+}$and $\mathrm{Ca}^{2+}$ ions, that had originated from the hydration of the glass particles. The hydrolysis of PDLLGA might have been accelerated by water dissolved in the hexafluoro-2-propanol used for mixing. During this mixing process, the PDLLGA molecular chains were supposed to be broken not only by mechanical impact but also by such chemical reaction. It is, therefore, believed that the molecular weight of PDLLGA became extremely low, and the hydrolysis of the polymer was remarkably rapid in TBS, resulting in a decrease in pH. Preparation of a composite material using BG-Na as the source of therapeutic ions has various advantages and weaknesses, that need to be discussed.
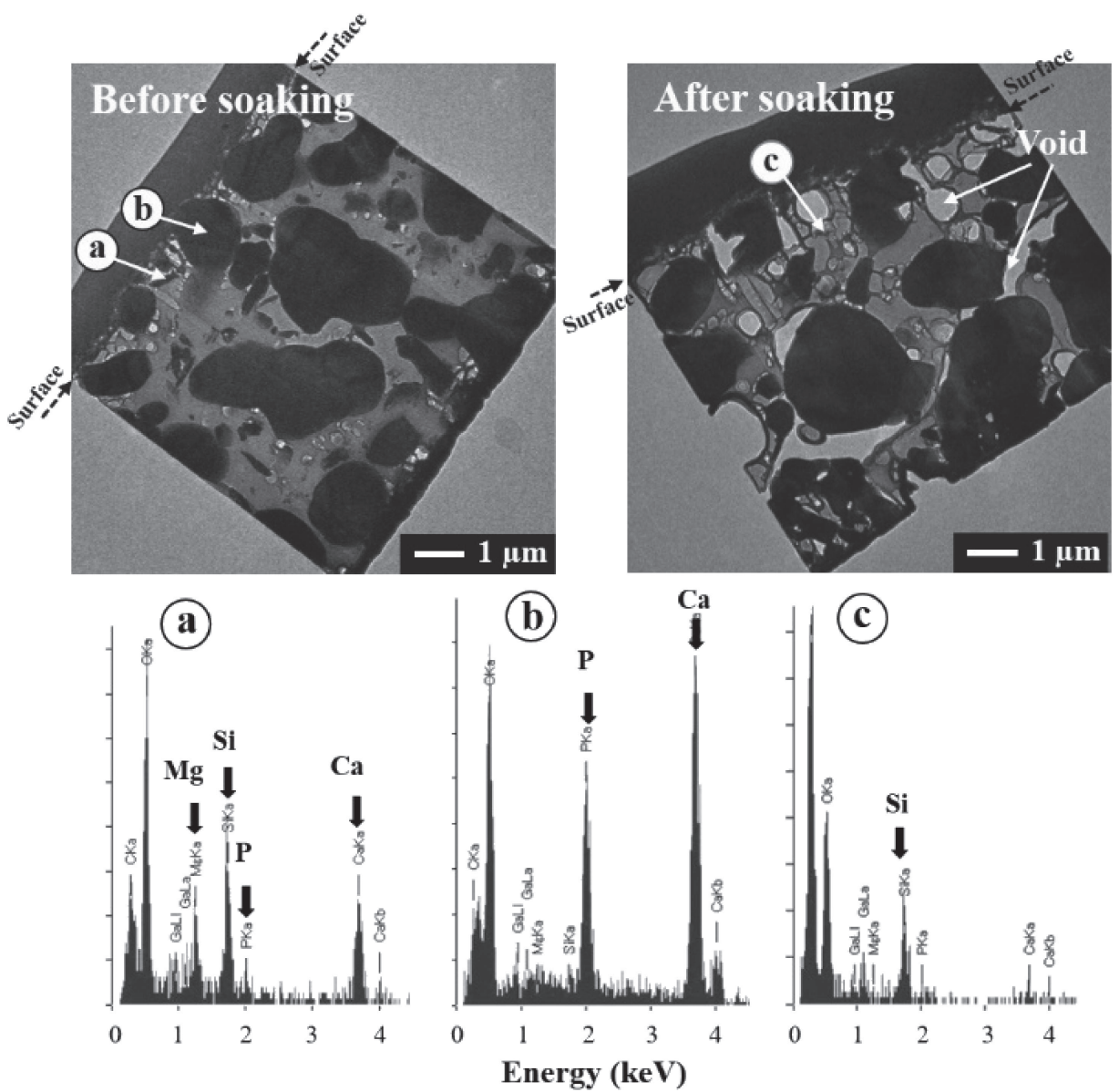

Fig. 4 TEM bright images of FIB-polished cross-sections before and after soaking BG-Mg/TCP/PDLLGA in Tris-HCl buffer solution for

$7 \mathrm{~d}$, and EDX spectra collected from positions (a)-(c) shown in the images. 
Next, we discuss the ion releasing behavior of the composite material containing BG-Mg in TBS. At $\mathrm{pH} \sim 7$, the solubility of $\beta$-TCP ${ }^{23)}$ was considerably lower than that of the glass, and most of the ion release during a short period of $7 \mathrm{~d}$ originated from the glass dissolution. The TEM observation (Fig. 4) showed that, in the composite material, the inorganic particles were well distributed in the polymer matrix phase, with few aggregations. Therefore, no percolation effect due to the aggregation of inorganic particles and no burst dissolution immediately after soaking occurred. Since many voids were observed after the soaking, PDLLGA was hydrolyzed to penetrate water into the material, and ions were released from the glass particles. $\mathrm{Ca}^{2+}$ and $\mathrm{Mg}^{2+}$ ions were continuously released for 7 days from the glass particles around the surface and inside the material, through ion exchange with protons. It was estimated from Fig. 3 that approximately $90 \%$ of $\mathrm{Ca}^{2+}$ and $\mathrm{Mg}^{2+}$ ions in the BG-Mg particles in the composite material were released in 7 days. On the other hand, the $\mathrm{Si}-\mathrm{O}-\mathrm{Si}$ bonds forming the glass network were believed to be hydrolyzed by the entry of water, resulting in the formation of $\mathrm{Si}-\mathrm{OH}$ groups, that were then partially released. The amount of silicate ions released from the material in $7 \mathrm{~d}$ was estimated from Fig. 3 to be $\sim 7 \%$ of the total $\mathrm{SiO}_{2}$ content in the BG-Mg particles. In addition, the $\mathrm{Si}-\mathrm{OH}$ groups partially dehydrated and condensed into a gel, that remained in the material. This is supported by the results of TEM observation (EDX spectrum (c) in Fig. 4) after the soaking. Therefore, the released amount of silicate ions was controlled at a low level.

$\mathrm{Ca}^{2+}, \mathrm{Mg}^{2+}$, and silicate ions have been reported as inorganic ions that enhance the growth of osteoblasts and osteoblast-like cells. ${ }^{24)} \mathrm{Ca}^{2+}$ and silicate ions enhance the proliferation, differentiation, and calcification of osteoblastlike cells. ${ }^{25,26)}$ Meanwhile, $\mathrm{Mg}^{2+}$ ions enhance cell adhesion $^{27)}$ and might also enhance calcification. ${ }^{28,29)}$ When a trace amount of silicate ions is present, ${ }^{30,31)}$ bone-forming ability is reported to be enhanced.

We reported the combined effects of $\mathrm{Si}-\mathrm{Ca}-\mathrm{Mg}$ ions on the mineralization process of osteoblast-like cells. ${ }^{32,33)}$ The presence of $\mathrm{Mg}^{2+}$ ions, the combination of three kinds of ions, and the presence of only $\mathrm{Ca}^{2+}$ ion or the combination of $\mathrm{Ca}^{2+}$ and silicate ions at the adhesion, proliferation, and calcification stages, respectively, were reported to induce excellent cell activation effects. To further enhance bone formation, it is important to optimize the inorganic ions releasing behavior. In this work, $\mathrm{BG}-\mathrm{Mg}$ was one of the candidates for the ion source. Optimization of the ionreleasing amount for cell activation is currently in progress, through the investigation of the appropriate glass content in the composite material.

\section{Conclusion}

In this work, $\beta$-TCP/PDLLGA composite materials containing a small amount of glass particles were prepared, to obtain a material that can activate bone-forming cells at the initial stage after implantation in a living body. During preparing the composite materials, blending Bioglass ${ }^{\circledR} 45 \mathrm{~S} 5$ glass particles significantly reduced the molecular weight of
PDLLGA. The resulting composite material showed high degradability and acidified the aqueous solution, TBS, in which it was soaked. On the other hand, when a composite material, containing glass particles with a composition in which $\mathrm{Na}_{2} \mathrm{O}$ in $45 \mathrm{~S} 5$ was substituted with $\mathrm{MgO}$, was soaked in TBS, $\mathrm{Ca}^{2+}, \mathrm{Mg}^{2+}$ and silicate ions were released continuously. The released amount of silicate ions was controlled compared to those of $\mathrm{Ca}^{2+}$ and $\mathrm{Mg}^{2+}$ ions. 46.1 $\mathrm{SiO}_{2} \cdot 24.4 \mathrm{MgO} \cdot 26.9 \mathrm{CaO} \cdot 2.6 \mathrm{P}_{2} \mathrm{O}_{5}$ glass particles are expected to be one of the important candidates to be a source of therapeutic ions for enhancing bone formation.

\section{Acknowledgment}

This work was supported, in part, by the NEDO project P15010 and its complementary project.

\section{REFERENCES}

1) D. Buser, B. Hoffmann, J.P. Bernard, A. Lussi, D. Mettler and R.K. Schenk: Clin. Oral Implants Res. 9 (1998) 137-150.

2) K. Rezwan, Q.Z. Chen, J.J. Blaker and A.R. Boccaccini: Biomaterials 27 (2006) 3413-3431.

3) S.J. Peter, L. Lu, D.J. Kim and A.G. Mikos: Biomaterials 21 (2000) 1207-1213.

4) Y.M. Khan, D.S. Katti and C.T. Laurencin: J. Biomed. Mater. Res. A 69 (2004) 728-737.

5) F.A.D. Santos and M.I.B. Tavares: Polímeros 24 (2014) 561-566.

6) P. Gentile, V. Chiono, I. Carmagnola and P.V. Hatton: Int. J. Mol. Sci. 15 (2014) 3640-3659.

7) D.K. Gilding and A.M. Reed: Polymer 20 (1979) 1459-1464.

8) R.A. Miller, J.M. Brady and D.E. Cutright: J. Biomed. Mater. Res. 11 (1977) 711-719.

9) A.G. Mikos, M.D. Lyman, L.E. Freed and R. Langer: Biomaterials $\mathbf{1 5}$ (1994) 55-58.

10) M.M. Stevens: Mater. Today 11 (2008) 18-25.

11) L.L. Hench, R.J. Splinter, W.C. Allen and T.K. Greenlee: J. Biomed. Mater. Res. 5 (1971) 117-141.

12) D.S. Brauer: Angew. Chem. Int. Ed. 54 (2015) 4160-4181.

13) N. Osada, A. Terada, H. Maeda, A. Obata, Y. Nishikawa and T. Kasuga: R. Soc. Open Sci. 6 (2019) 190612.

14) C.-C. Lin, S.-F. Chen, K.S. Leung and P. Shen: J. Mater. Sci.: Mater. Med. 23 (2012) 245-258.

15) N. Trcera, S. Rossano and M. Tarrida: J. Raman Spectrosc. 42 (2011) $765-772$.

16) H. Yamashita, H. Yoshino, K. Nagata, I. Yamaguchi, M. Okawa and T. Maekawa: J. Ceram. Soc. Jpn. 106 (1998) 539-544.

17) H. Aguiar, E.L. Solla, J. Serra, P. González, B. León, F. Malz and C. Jäger: J. Non-Cryst. Solids 354 (2008) 5004-5008.

18) A. Dietzel: Z. Elektrochem 48 (1942) 9-23.

19) A. Pedone, T. Charpentier, G. Malavasi and M.C. Menziani: Chem. Mater. 22 (2010) 5644-5652.

20) M.A. Karakassides, A. Saranti and I. Koutselas: J. Non-Cryst. Solids 347 (2004) 69-79.

21) I. Wacławska and M. Szumera: J. Therm. Anal. Calorim. 84 (2006) 185-190.

22) S.J. Watts, R.G. Hill, M.D. O’Donnell and R.V. Law: J. Non-Cryst. Solids 356 (2010) 517-524.

23) L.C. Chow: J. Ceram. Soc. Jpn. 99 (1991) 954-964.

24) A. Hoppe, N.S. Güldal and A.R. Boccaccini: Biomaterials 32 (2011) 2757-2774.

25) S. Maeno, Y. Niki, H. Matsumoto, H. Morioka, T. Yatabe, A. Funayama, Y. Toyama, T. Tagushi and J. Tanaka: Biomaterials 26 (2005) 4847-4855

26) P. Han, C. Wu and Y. Xiao: Biomater. Sci. 1 (2013) 379-392.

27) H. Zreiqat, C.R. Howlett, A. Zannettino, P. Evans, G. Schulze-Tanzil, C. Knabe and M. Shakibaei: J. Biomed. Mater. Res. 62 (2002) 175184. 
28) S. Yamada, A. Obata, H. Maeda, Y. Ota and T. Kasuga: Front. Bioeng. Biotech. 3 (2015) 195.

29) S. Yamada, Y. Ota, A. Obata and T. Kasuga: Biomed. Mater. Eng. 28 (2017) 47-56.

30) R. Jugdaohsingh, K.L. Tucker, N. Qiao, L.A. Cupples, D.P. Kiel and J.J. Powell: J. Bone Miner. Res. 19 (2004) 297-307.

31) A. Obata, N. Iwanaga, A. Terada, G. Jell and T. Kasuga: J. Mater. Sci. 52 (2017) 8942-8956.
32) A. Obata, T. Ogasawara, S. Yamada and T. Kasuga: Ceramic Engineering and Science Proceedings 37 (2017) pp. 107-112 (Proceedings of the 40th International Conference on Advanced Ceramics and Composites (ICACC), ed. by J.C. LaSalvia, R. Narayan, P. Colombo, M. Fukushima and A. Gyekenyesi, The American Ceramic Society, OH, 2017).

33) A. Obata, T. Ogasawara and T. Kasuga: J. Biomed. Mater. Res. A 107 (2019) 1042-1051. 